\title{
MEMÓRIA, EMPODERAMENTO E ÉTICA NA OBRA DE LÍDIA JORGE
}

\author{
Maria Graciete Besse \\ (Universidade de Paris - Sorbonne)
}

\section{RESUMO}

Neste ensaio, pretendemos observar de que modo Lídia Jorge mobiliza a memória para interrogar a violência patriarcal, a experiência colonial e pós-colonial ou ainda as identidades em crise na sociedade portuguesa, reconfigurando uma consciência crítica com fortes implicações axiológicas.

PALAVRAS-CHAVE: memória, ética, empoderamento

\begin{abstract}
In this essay, we intend to observe how Lidia Jorge mobilizes memory to interrogate patriarchal violence, experience colonial and post-colonial or identities in crisis in portuguese society, reconfiguring a critical awareness with strong axiological implications.
\end{abstract}

KEYWORDS: memory, ethics, empowerment 
Faire sa propre histoire n'est possible qu’à la condition de l'héritage.

Jacques Derrida

Só pretendo ser testemunha do mundo.

Lídia Jorge

O conceito polissémico de empoderamento, cujas raízes mergulham na reforma protestante do século XVI, tem sido mobilizado desde os anos 1970 pelos movimentos feministas e negros, alimentando a reflexão em diversos domínios das ciências humanas e socias, para além de uma utilização concreta na esfera da política social, educativa ou humanitária, com vista à transformação emancipatória de pessoas e comunidades. Enquanto prática que não deixa de ser criticada por alguns teóricos que nela identificam a legitimação de um certo neo-liberalismo (ROMANO, 2002), o empoderamento pode significar tanto o poder que se confere ao outro, como o processo de tomada de consciência através do qual as pessoas ganham voz, visibilidade, influência e capacidade de acção, ou seja controle sobre as suas vidas (WALLERSTEIN e BERNSTEIN, 1994). Este processo passa pela "educação libertadora" e pela "pedagogia situada" que implicam, antes de mais, uma percepção crítica da realidade social (FREIRE, 1981). Sem entrar na discussão desta problemática rica e complexa, importa-nos interrogar até que ponto algumas obras literárias são capazes de promover o empoderamento do leitor, ao mobilizar a memória para testemunhar sobre as tensões da sociedade e dar visibilidade aos sujeitos mais vulneráveis.

Desde o seu primeiro romance, $O$ dia dos prodígios (1980), a romancista portuguesa Lídia Jorge, interroga a violência patriarcal, a memória colonial e pós-colonial ou ainda as identidades em crise na sociedade hegemónica, de forma a reconfigurar uma consciência crítica com fortes implicações éticas, fazendo viajar o leitor através de uma notável experiência do tempo que revela as importantes mudanças verificadas em Portugal entre os anos 50 e a actualidade. Ao evocar a sua vocação de escritora, Lídia Jorge lembra um episódio da sua infância num belíssimo texto intitulado "Os dois lados do mundo", que passamos a citar:

A Escola da Cabeça d’Águia era uma casa com uma porta, duas janelas e mais nada. No primeiro dia em que me levaram até lá, fiquei feliz porque ia encontrar crianças da minha idade. Elas lá estavam, divertidas, barulhentas, grandes olhos, faces magras. Também era a primeira vez que me colocavam na mão uma caneta de tinta de molhar e ela escorregou-me da mão, borrou a folha, e rebolou pelo chão. Tive de gatinhar debaixo das carteiras para a encontrar. Foi então que eu reparei que a maior parte dos pés dos meus colegas estavam descalços. Vi os seus pés pousados no chão e 
percebi que a turma se dividia em duas metades - os que tinham e os que não tinham sapatos. Nessa noite, procurei sapatos em casa que servissem aos meus colegas, e havia várias caixas, mas de criança encontrei um par, e eu queria encontrar botas, sapatos vários. A minha mãe descobriu o que eu andava a fazer e disse-me - "Para quê tudo isso? Desengana-te, por mais que faças, nunca vais calçar toda a gente". E assim foi. Passei muitos anos sem contar este episódio, até que desisti desse silêncio. Passado todo este tempo, a $\mathrm{Hu}-$ manidade continua a dividir-se, exactamente, nesses mesmos dois grupos - os que andam e os que não andam descalços. Só na Literatura conseguimos encontrar sapatos para todos. Talvez essa seja uma das razões por que escrevo. Talvez escreva desde aquele dia em que a caneta escorregou pelo tampo espalhando tinta no papel e conduzindo-me ao chão do mundo. ${ }^{1}$

Mas pode a literatura oferecer realmente sapatos ou botas de sete léguas ao leitor? Tal questão retoma uma problemática que atravessa os estudos literários desde há muito e que consiste em saber que valores podem os escritores verdadeiramente transmitir quando se interessam pelo "chão do mundo". No final dos anos 40, Jean-Paul Sartre insiste no compromisso inevitável do artista definido como um homem livre que se dirige a homens livres (SARTRE, 1948). Algumas décadas mais tarde, Alain Finkielkraut interroga-se sobre a maneira como os escritores transformam o mundo, não já na perspectiva do engajamento político de Sartre, mas em função das estratégias com que reorganizam nos seus livros a percepção dos seres e dos valores sociais (FINKIELKRAUT, 2006).

A relação estabelecida entre a literatura e a vida interessa igualmente Roland Barthes que, numa conferência de 1978, sublinha o seu desejo de escrever um romance capaz de dizer simultâneamente o amor e a morte, através de uma forma que, segundo os seus próprios termos, "recolhe o sofrimento e transcende-o" (BARTHES, 1984, p. 335). Na sua opinião, o romance deve responder a três objectivos : testemunhar sobre os grandes mudos da História e salvá-los do esquecimento; dizer abertamente os afectos; e, por fim, exprimir "o brilho e o sofrimento do mundo" (BARTHES, 1984, p. 346). Por conseguinte, graças à memória, ao testemunho e à transmissão, a literatura pode efectivamente ajudar o leitor a tomar consciência das relações de poder na sociedade que o rodeia e eventualmente a posicionar-se perante as injustiças. Adoptando esta perspectiva, Antoine Compagnon intitula a sua lição inaugural no Collège de France, em 2006, "La littérature pour quoi faire?", demonstrando que, ao dar forma às experiências humanas, a literatura efectivamente desconcerta e incomoda muito mais do que os discursos oriundos da filosofia, da sociologia ou da psicologia, pois ao solicitar as emoções e a empatia do leitor transforma-se no lugar por excelência da aprendizagem de si e do outro, de uma identidade obstinadamente em devir, dotada de um grande poder emancipatório (COMPAGNON, 2007). 
Toda a obra de Lídia Jorge ilustra este "poder emancipatório", ao privilegiar o terreno sociológico para, através da "crónica do tempo que passa" (FERREIRA, 2009, p. 335), testemunhar sobre a História, a identidade, o segredo, a corrupção, a liberdade, a violência, o sentido da responsabilidade, entre muitos outros temas que atravessam toda a sua escrita. Desde O dia dos prodígios, que fascinou de imediato a crítica em 1980, até ao seu último romance, $A$ noite das mulheres cantoras, publicado em 2011, a obra de Lídia Jorge, coroada por numerosos prémios literários, caracteriza-se por uma grande coerência temática e por uma tonalidade eminentemente ética, veiculada por um olhar que transforma a herança recebida do passado, mobiliza valores fundamentais e transmite ao leitor uma consciência crítica do mundo.

Apesar das dúvidas sobre a capacidade da ficção em representar o "real", muitos estudiosos consideram que a retórica textual pode induzir performativamente o sentido da responsabilidade, interessando-se assim pelas implicações éticas da literatura enquanto possibilidade de abertura ao Outro e de transformação existencial. A problematização das relações entre literatura e ética tem dado lugar a diversas abordagens teórico-críticas, retomando um questionamento que já se encontra na Antiguidade, nomeadamente na abertura do livro II da Etica a Nicómaco, de Aristóteles, que associa a ética ao hábito adquirido e à natureza de cada ser. Reformulada depois por Cícero em termos de moral, a noção de ética vai-se modificando ao longo dos tempos para alimentar, sobretudo em meados do século XX, uma série de debates sobre a função da obra de arte, e culminar nas perspectivas do care que hoje se debruçam sobre a vulnerabilidade e a solicitude, consideradas por alguns como qualidades essencialmente femininas.

Se, para autores como Brecht ou Sartre, a implicação ética e política do artista é absolutamente necessária, para outros, como Adorno, a arte comprometida não transforma o mundo, pois em vez de propôr alternativas, a sua função consiste antes de mais em resistir à opressão (ADORNO, 1984, p. 289). A filosofia moral contemporânea, nomeadamente norte-americana, tem-se interrogado sobre essas questões, propondo, desde os anos 80, algumas reflexões interessantes que adoptam ora a via desconstrucionista de orientação sócio-política (FELMAN e LAUB, 1992), ora a perspectiva neo-aristotélica que envereda por um caminho claramente existencial (NUSSBAUM, 2010), considerando que a literatura desempenha um papel essencial no desenvolvimento moral dos leitores. Convém, no entanto, não esquecer que uma obra literária é sempre uma forma de linguagem em acção, como mostrou Paul Ricœur (1983), partindo do princípio de que a História só se torna acessível quando narrativizada. Na verdade, o leitor não vai encontrar na ficção quaisquer exemplos, soluções ou receitas para as suas interrogações, mas graças à articulação do sensível e do intelegível, a escrita permite, como afirma o filósofo francês, "re-configurar" a experiência temporal e transmitir uma melhor compreensão do mundo, graças 
à representação axiológica dos problemas humanos. Sem entrarmos agora nesta discussão que foi desenvolvida em particular por Sandra Laugier (2006) e por Carole Talon-Hugon (2009), interessa-nos apenas aqui considerar, na esteira de Levinas, que a literatura abre efectivamente um acesso privilegiado ao "fundo obscuro da existência" (LEVINAS, 1986, p. 98). A partir dessa proposta, tentaremos questionar o fazer literário de Lídia Jorge que, apesar de não subordinar a sua escrita a qualquer implicação política, religiosa ou filosófica, manifesta todavia o desejo de "testemunhar", oferecendo-nos uma perspectiva lúcida e responsável que responde, com grande sensibilidade e vigor estético, ao apelo do mundo que nos rodeia.

A conotação jurídica do testemunho, implicando etimologicamente uma voz que toma parte num processo para dizer a verdade, associa-se muitas vezes à figura do sobrevivente e ilustra uma tensão entre memória e esquecimento que tem animado, nos últimos anos, um intenso debate em torno da (in)viabilidade da palavra sobre a Shoah, que se alargou em seguida a outros massacres do século XX, criando uma "nova era", como observa Annette Wieviorka (1998). Na sequência de Primo Levi, o filósofo italiano Giorgio Agamben afirma que "o testemunho vale no essencial por aquilo que nele falta" (AGAMBEN, 1999, p. 36), constituindo portanto uma aporia, visto que a experiência dos campos de extermínio só poderia ser transmitida pelo "muçulmano", isto é, aquele que perdeu toda a espessura humana, a autêntica "testemunha integral" que não escapou à barbárie nazi. No entanto, muitos sobreviventes da catástrofe sentiram necessidade de testemunhar por razões éticas e imperativo moral, revelando simultâneamente um pacto com os que ficaram para trás e um compromisso com o tempo presente, mas também futuro, manifestando quase sempre um profundo sentimento de culpa por falarem no lugar daquele que nunca o poderá fazer. Tal impossibilidade foi sublinhada por diversos autores e analisada nomeadamente por Shoshana Felman e Dori Laub nos termos de uma operação do inconsciente do texto que, de forma aporética e sintomática, revela verdades históricas através de silêncios, lacunas e fragmentos, ou seja, indícios de um real irrepresentável (FELMAN e LAUB, 1992).

Para além do testemunho dramático daquele que viveu directamente o trauma decorrente de um "estado de excepção", importa-nos ter aqui em conta outro tipo de testemunho, decerto menos grave, de teor essencialmente "poético" que, segundo Jorge de Sena, se reveste contudo de alguma importância, pois é a "mais alta forma de transformação do mundo" (SENA, 1988, p. 25-26). Ao "re-configurar" uma realidade em processo de rápida transformação, a obra de Lídia Jorge interroga subtilmente a memória, pondo em evidência uma prática do descentramento e da responsabilidade, fundada numa axiologia alimentada pelo dever de testemunhar e pela re-invenção necessária da herança recebida, que exige sempre uma escolha e se apresenta como uma tarefa, tal como constata Derrida (1993). 


\section{FILIGRANAS DA MEMÓRIA}

No universo da sua ficção, Lídia Jorge mobiliza muitas vezes uma memória viva que se apresenta como a base da identidade pública e privada, definindo uma forma rebelde de ser e de estar no mundo, ${ }^{2}$ filtrando um tempo sensível que é transformado esteticamente graças a uma linguagem lúcida, irónica, por vezes cinematográfica e lírica, não desprovida de alguma melancolia. Da infância rural passada no interior do Algarve, a romancista resgata uma primeira herança feita de palavras, afectos e mentalidades com rasgos míticos bem presentes no seu primeiro romance, $O$ dia dos prodígios, onde descobrimos a densidade da memória colectiva de Vilamaninhos, uma comunidade arcaica, fechada sobre si mesma, alienada, supersticiosa, confrontada com a mudança indiciada por dois acontecimentos extraordinários: o misterioso aparecimento duma "cobra voadora" e o anúncio da Revolução dos Cravos feito por soldados "garbosos e épicos", identificados pelo imaginário da ceifeira Jesuína Palha como seres sobrenaturais, ${ }^{3} \mathrm{o}$ que leva Maria Alzira Seixo a considerar que esse romance "encara o 25 de Abril pelos olhos deslumbrados de uma alma popular que vê o acontecimento como um sonho fabuloso integrado no quotidiano" (SEIXO, 1986, p. 179). A narrativa mostra efectivamente como o passado bem cristalizado nas mentalidades rurais se defronta com as marcas de uma novidade vinda da cidade, difícil de entender, mas propiciadora de várias metamorfoses como a de Branca, mulher bordadeira, submissa, com poderes de vidente, que se liberta do marido pela força da palavra, anunciando um empoderamento individual, mas também colectivo, que ilustra a mudança do papel social da mulher na sociedade portuguesa depois do 25 de abril de 1974.

Se o excesso de memória e o peso da tradição caracterizam a comunidade de Vilamaninhos petrificada no passado, em contrapartida, em O Cais das Merendas, é um excesso de alteridade que vai desencadear o processo de aculturação ou desempoderamento que atinge os camponeses algarvios que, face às incertezas da subsistência, se deslocam das suas aldeias para trabalhar num hotel da beira-mar, onde alguns deles, como Sebastião Guerreiro, se envolvem com turistas inglesas que os utilizam sexualmente. A identidade rural vacila rapidamente perante os novos códigos culturais introduzidos nos anos 50 pela indústria turística, provocando o esquecimento e a perda dos valores tradicionais. A única personagem que resiste à alienação geral, Rosária, filha de Sebastião, acaba por se suicidar. Lídia Jorge mostra com alguma ironia como o apelo consumista e a atracção pelo estrangeiro, considerado superior, transformam os comportamentos, os percursos, os sentimentos e a própria línguagem dos ex-camponeses que abandonam o seu passado doloroso, ilustrado metonimicamente pelo termo "merenda", "coisa que lembraria figos", que passa a ser designada por "party, ajuntamento que falava festa, doces gestos" (JORGE, 1982, p. 25).

A perda identitária não se refere apenas aos rurais mas identifica-se também com figuras urbanas de extracto burguês, como a Lurdinhas, personagem apenas evocada em $A$ última Dona, que se sacrifica ao mito da 
fada do lar depois de casar com o Engenheiro Geraldes, como ele próprio reconhece quando se lembra dela na misteriosa Casa do Leborão onde passa alguns dias com a amante (JORGE, 1992, p. 258). Pontuado pelo campo semântico da recordação (o verbo "lembrar" é constantemente reiterado ao longo da narrativa), este romance de Lídia Jorge mobiliza fragmentos do percurso do engenheiro respeitável que vê gorado o seu plano de refazer a vida com a jovem Anita Starlet, a cantora aventureira e "coquine" que acaba por se suicidar num dos quartos do hotel disfarçado em clube de caça para pessoas importantes que procuram a invisibilidade. O incipit inaugura de imediato uma subjectividade, através da expressão "Sou testemunha", que legitima o trabalho da memória e a perplexidade do homem influente, a braços com a experiência de uma paixão serôdia, interrogando a consistência dos sentimentos e das sensações entre digressões especulativas, reminiscências e situações pontuadas por uma estranheza favorecida pelo mistério que rodeia o "local secreto" onde "o serviço era tão discreto que sempre que necessário os criados serviam vendados” (JORGE, 1992, p. 186). O desenlace trágico é narrado de forma elíptica, à semelhança do que descobrimos também num outro livro da autora, Marido e outros contos, no qual Lúcia, a porteira alienada, é incapaz de aceitar a compaixão dos vizinhos do prédio que a tentam ajudar a empoderar-se, ou seja, a libertar-se de um companheiro alcoólico e violento, por não imaginar sequer a possibilidade de viver sem ele (JORGE, 1997). Nesta narrativa, a sedimentação do vivido é desvendada por meio de uma oração em latim macarrónico que alterna com o monólogo interior da porteira e as sugestões dos vizinhos, criando um espaço sonoro onde se inscreve uma outra forma de petrificação do passado que se conjuga, inevitavelmente, com a dominação masculina.

A situação das mulheres, partilhadas entre o passado e o presente, atravessa ainda outros textos de Lídia Jorge, como Notícia da cidade silvestre, em que assistimos ao questionamento de uma identidade em crise e à possibilidade de empoderamento através do percurso sentimental de Anabela Cravo e Julia Grei, duas amigas que lutam pela sobrevivência e ilustram a busca de uma nova forma de vida na Lisboa pós-74, época em que "os jornais eram outros e as pessoas mudavam" (JORGE, 1984, p. 15), vivendo uma multiplicidade de experiências políticas, afectivas e artísticas.

A revisitação da memória individual e colectiva ilustra por vezes a perda da inocência, como no caso de Eva Lopo que reconfigura vinte anos mais tarde o que foi a sua experiência da guerra colonial num hotel da Beira, em Moçambique, no tempo em que se chamava Evita (JORGE, 1988). Ao desconstruir a narrativa inicial, "Os Gafanhotos", a narradora propõe um balanço do seu percurso existencial, mas também uma desmistificação irónica e impiedosa do mito imperial transmitido pela história oficial, como já o assinalaram numerosos críticos. ${ }^{4}$ Ao longo da sua evocação do passado, entre lembrar e esquecer, Eva Lopo não só considera que a verdade é uma ilusão dos sentidos, como questiona a validade da sua própria memória, visto que "a pouco e pouco as palavras isolam-se dos objectos 
que designam, depois das palavras só se depreendem sons, e dos sons restam só os murmúrios, o derradeiro estádio antes do apagamento."(JORGE, 1988, p. 259). Neste romance, o choque dos tempos e dos pontos de vista sobre a violência permite distingir claramente dois ethos: enquanto o narrador inicial de terceira pessoa oferece um quadro geral centrado na festa de casamento de Evita e Luis Alex no terraço do hotel Stella Maris, transmitindo uma percepção masculina e ortodoxa dos acontecimentos, em contrapartida, a rememoração de Eva Lopo afirma um posicionamento rebelde e uma visão feminina da guerra, sublinhando de forma heterodoxa os sinais da mudança e reavaliando com muita ironia o significado ético e político daquele momento histórico.

Noutros casos, o trabalho da memória escreve-se como aventura magoada que mergulha na busca de uma filiação, passando pela explicitação de um segredo e transformando-se numa fecunda reflexão sobre a herança ou sobre a fama, tal como acontece respectivamente em $O$ vale da paixão e A noite das mulheres cantoras, nos quais encontramos algumas figuras femininas dotadas de grande densidade psicológica e notável capacidade emancipatória. Em $O$ vale da paixão, a anamnese alimenta-se da ferida existencial de uma narradora-protagonista sem nome, referida sempre como "a filha de Walter", que tenta elucidar o segredo da casa de Valmares, situada perto de Faro, a partir de um duplo movimento de construção e desconstrução da figura paterna ausente, o aventureiro Walter Dias que partiu para a India em 1945, abandonando a ruralidade arcaica e deixando grávida a jovem Maria Ema que, para salvar a honra da família, é obrigada a casar com o filho mais velho do patriarca Francisco Dias, sugestivamente chamado Custódio, coxo e generoso, o único que não emigra para o estrangeiro à semelhança dos irmãos. Apesar da distância, o pai ausente e "trotamundos" transmite à filha biológica a força de um imaginário, representado por uma série de objectos de que ela se sente "a herdeira universal" (JORGE, 1998, p. 24). O tema da herança, omnipresente neste romance da ausência que é $O$ vale da paixão, declina-se a partir do momento em que a narradora toma consciência das marcas da sua filiação e descobre-se proprietária de um legado que é antes de tudo uma força que lhe permite agir, viver e sobretudo escrever. $\mathrm{O}$ esquema matricial da narrativa é constituído pela ausência do pai, que remete para o que Lacan designa como o Outro interno, transformado em valor supremo, e por conseguinte, supremamente idealizado, mas apoia-se igualmente no acto dinâmico da rememoração, pelo qual a narradora reabilita a figura paterna para em seguida a destruir e assim se libertar.

Partilhada entre duas figuras masculinas, a primeira, eufórica, representada pelo genitor (Walter, o aventureiro), a segunda mais ambígua, representada pelo pai social (Custódio, o guardião da casa patriarcal), a narradora propõe-nos uma composição simétrica que se organiza em torno de um eixo central fundado na evocação obsessiva da noite chuvosa de 1963, em que Walter, regressando pela última vez a Valmares, sobe clandestinamente ao quarto da filha-sobrinha : 
A chuva ia e vinha [...] e ele acrescentou, com o candeeiro levantado e os olhos cravados nos dela - "Nunca te dei nada". E ela continuava completamente surpreendida, pois sabia que não era assim, e quis mostrar como não era assim, como estava rodeada de objectos e seres deixados por ele, imagens, ideias e fundamentos, tecidos e desenhos [...], e se tinha desejado aquele encontro, era só para lhe explicar como vivia com ele, na ausência dele, por tudo isso que possuía. (JORGE, 1998, p. 16)

A atmosfera algo incestuosa desta cena fundadora atravessa a busca da personagem que, numa tentativa de elucidação do seu passado, procura ao mesmo tempo a sua verdade. Temos assim acesso à narrativa da infância, da adolescência e da conquista de uma afirmação de identidade na idade adulta, a partir de um duplo movimento de construção/desconstrução da figura paterna. Pouco a pouco, a busca transforma-se laboriosamente em inquérito, de forma a elucidar o mistério que rodeia a existência de Walter Dias, dando-lhe uma voz, ligando-o e, ao mesmo tempo, transmitindo, purificando, cauterizando a ferida da ausência e do abandono. Através de uma narração em claro-obscuro, que oscila entre a primeira e a terceira pessoa, o leitor tem acesso à densidade de uma existência povoada de aventuras que remetem tanto para a experiência individual como para a história colectiva portuguesa em vias de transformação. $O$ presente da escrita cria um ritmo "gaguejante" (FIGUEIREDO, 2011, p. 181), feito de intervalos regulares, alimentado por fragmentos heterogéneos da memória, que se sucedem uns aos outros sem ordem aparente, incansavelmente retomados, repetidos, num movimento contínuo de expansão, trabalhado por um processo de perda em que a voz da narradora se liberta no jogo das tensões, das relações, das repetições, propondo-nos um dispositivo singular, rizomático, constituído por aquilo que Deleuze define como "pregas", ou seja as estratificações onde se reinventa incessantemente uma relação singular com o tempo. A escrita assinala-se portanto sob o duplo signo da rememoração e da comemoração, deixando-se apreender graças a uma memória subjectiva que desenha a presença do Mesmo e permite o encontro com o Outro, numa trajectória que conduz à intimidade mais profunda do ser. Através da recriação do passado, a narradora busca a sua identidade, mas fornece também um testemunho sobre o autoritarismo e a agonia da sociedade salazarenta, ao mesmo tempo que procura um remédio para salvar da infâmia o seu tio-pai biológico, acusado de incesto nas cartas dos familiares que emigraram. Tal percurso introspectivo não é inofensivo, revelando-se enquanto pharmakón, como diria Derrida (1972), isto é, remédio que salva do esquecimento mas também veneno que cria uma desordem geradora da escrita-parricida (os três contos entregues ao "trotamundos" na Argentina), via de acesso à libertação identitária.

Em A noite das mulheres cantoras, Lídia Jorge mergulha indirectamente na experiência de várias gerações de portugueses em Africa, para nos oferecer o longo monólogo de Solange de Matos, filha de antigos colo- 
nos em Angola, que evoca a aventura da banda feminina de que fez parte, composta por jovens retornadas e uma cantora africana, e que chegou a gravar um disco no final dos anos 80 sob a direcção de Gisela Batista, a maestrina determinada que não olha a meios para concretizar a sua ambição de celebridade. A partir da "noite perfeita" (JORGE, 2011) que ocorre 21 anos mais tarde graças a um programa televisivo, a rememoração fragmentada de Solange assemelha-se a um percurso de aprendizagem que revisita as diferentes etapas da vida do grupo, marcadas pelas relações de poder e alguns sobressaltos, como a morte da cantora Madalena Micaia em condições dramáticas.

Em qualquer desses exemplos, a escritora não se limita apenas a recordar o passado nas suas diferentes camadas sobrepostas ou rizomáticas, em função da coerência das intrigas ou das escolhas subjectivas do narrador. Com grande subtileza, a escrita transforma quase sempre esse passado em motivo de reflexão crítica, conferindo-lhe a espessura da "experiência de um tempo incorporado" ${ }_{5}^{5}$ que é também a experiência sempre renovada do leitor. A tensão entre a lembrança e o esquecimento remete assim para diferentes níveis de significação da história, evidenciando tanto questões políticas como morais, sempre identificadas com espaços de grande violência física e psicológica onde Lídia Jorge inscreve uma exigência ética e a necessidade de reinventar a dignidade humana.

\section{TOPOGRAFIAS DO TESTEMUNHO}

Os espaços privilegiados pela escritora - Algarve, Lisboa e Moçambique - formam um triplo eixo resultante do confronto de olhares e sensações, cruzando com grande visualidade os tempos e a apreensão dos afectos na revisitação crítica da história, que se escreve quase sempre como uma experiência da perda em que se questionam as certezas, as ilusões, a identidade, e se pode aniquilar mesmo a vida. Quer se trate de um espaço rural, urbano ou de guerra, o olhar de Lídia Jorge, ou melhor o "olhar da espia”, segundo as suas próprias palavras, ${ }^{6}$ resgata do silêncio os contornos porosos da estranheza e da diferença, desenhando uma paisagem alimentada por uma percepção lucidamente trabalhada pelo posicionamento ético que revela não só o visual, mas também todos os sentidos e os múltiplos movimentos do corpo, de forma a apreender a "carne do mundo".

Num conhecido estudo sobre poesia, o poeta e crítico francês Michel Collot observa que a paisagem e a subjectividade são indissociáveis, a tal ponto que "a paisagem é o lugar de uma troca em duplo sentido entre o eu que se objectiviza e o mundo que se interioriza." (COLLOT, 2005, p. 52) Também na obra de Lídia Jorge podemos identificar esse duplo movimento, criador de uma "constelação original"' feita de imagens do mundo e de um sujeito que se espacializa na escrita, ultrapassando o registo biográfico ou circunstancial para se afirmar através de um processo híbrido de desdobramento ético e estético que pretende testemunhar sobre uma certa 
verdade do mundo contemporâneo. Ao configurar-se como o resultado de um olhar singular que se desloca sobre a variedade de significados latentes na referencialidade, a paisagem escrita por Lídia Jorge corresponde frequentemente a uma percepção inquieta que evidencia uma dimensão sociológica, mas também lírica, em que se investe a totalidade de um sujeito identificado com lugares da memória que podem ser exteriores (a cidade, a praia, o campo), ou interiores, como a casa, "valor vivo", verdadeiro cosmos e nosso primeiro universo que funciona à maneira de um grande arquivo de lembranças pessoais, como mostrou Bachelard em 1957, podendo funcionar ainda como alegoria do próprio país. ${ }^{8}$

Alguns estudiosos já observaram que são diversas as representações das casas na obra da escritora, podendo assumir várias funções, positivas ou negativas. Encontramos assim a casa-altar de Carminha Rosa e Carminha Parda ( $O$ dia dos prodígios), o atelier-estado de alma onde vive Julia Grei com o filho (Notícia da cidade silvestre), a Fábrica, espaço vital ocupado pelos Mata (O vento assobiando nas gruas), a Casa da Praia, abrigo para duas "pessoas em perigo" (Combateremos a sombra), ou ainda a garagem da Casa Paralelo, frente ao Tejo, onde o grupo de Solange ensaia as suas coreografias num clima de "entusiasmo extravagante" (A noite das mulheres cantoras). Mas as casas inventadas por Lídia Jorge podem também revelar-se como "assombradas", espaços espectrais de ameaça que alimentam a topografia do testemunho, como o hotel Stella Maris, onde se ouvem ecos da crueldade colonial (A costa dos murmúrios); a casa patriarcal de Valmares progressivamente abandonada pela maioria dos seus habitantes que partem para o estrangeiro ( $O$ vale da paixão); a inquietante casa do Leborão com as suas práticas secretas capazes de subtilizar cadáveres ( $A$ última Dona); a casa das Araras povoada de artistas que se interrogam sobre o sentido da representação (O jardim sem limites), sem esquecer o gabinete de Osvaldo Campos, o psicanalista indignado de Combateremos a sombra, que, ao descobrir através de uma paciente o tráfico clandestino praticado em Lisboa por gente importante, decide tomar posição face à desmedida, vendo-se enredado num enigma policial que explora as relações entre o desejo, a solicitude e a morte, acabando por ser misteriosamente assassinado numa sexta-feira santa.

Para além das casas caracterizadas pela oscilação entre a ordem e a desordem, a paisagem romanesca de Lídia Jorge condensa-se por vezes num espaço metonímico onde a testemunhal "matéria-emoção" (COLLOT, 1997a) se apresenta directamente como uma herança problemática, ilustrada por cicatrizes, fotografias secretas, ou ainda por objectos pessoais como uma manta de soldado e outros elementos aparentemente insignificantes, abandonados ao longo de uma vida. Assim, a cicatriz orgulhosamente ostentada pelo capitão Forza Leal em A costa dos murmúrios é bem representativa do poder colonial e da falsa heroicização de um "tempo da cegueira", de par com a cicatriz invisível, resultado do parto abortado da mulher do tenente Zurique, ilustrando a história, também ela invisível, "protagoniza- 
da pelas mulheres, traçada no interior da casa” (RIBEIRO, 2004, p. 371). Essas marcas corporais indiciam uma violência que culmina nos testemunhos do massacre de Wiriamu relatado tanto pelo alferes Góis em termos de "limpeza", como pelas fotografias secretas que Helena de Tróia, a mulher do capitão, mostra a Evita, num momento de cumplicidade, revelando-lhe imagens de "aldeias em chamas" e de um "soldado [Luis Alex] com a cabeça dum negro espetada num pau” - dotadas de evidentes ressonâncias ético-políticas que denunciam o absurdo da guerra colonial, a abjecção praticada pelos militares portugueses ou simplesmente a crueldade humana. Com efeito, a fotografia de guerra é um traço do real que, tal como sublinhou Susan Sontag, desloca a imagem do seu contexto original para evocar uma experiência da dor universal, veiculando sempre um conteúdo moral (SONTAG, 2003, p. 63).

Ao revisitar de novo o Algarve natal em O vale da paixão, "livro-síntese de várias experiências", como afirmou a própria escritora, ${ }^{10}$ a reflexão de Lídia Jorge sobre o legado do passado desenha um "romance-herança" que "de forma mais poética se dirige ao futuro" (FERREIRA, 2009, p. 18-19). A identidade que nele se constrói é tributária da herança silenciosa representada sobretudo pela manta de soldado que a narradora enterra no final, segundo um ritual funerário em eco à Ilíada, que atravessa parodicamente todo o tecido textual, mas forja-se também a partir dos objectos relacionados com a figura do pai, saturados de valor simbólico, como a fotografia de 1951, tirada clandestinamente em Faro e que reune a família nuclear; o espelho de 1963 em que se reflecte a semelhança física entre o pai e a filha; o Album dos Pássaros que forma o roteiro imaginário das viagens de Walter Dias; ${ }^{11}$ o uniforme devorado pela traça no armário do quarto; o revólver Smith, escondido debaixo do colchão, objecto fálico que "povoa o imaginário da filha incestuosamente ligada à imagem desejada do pai" (FIGUEIREDO, 2011, p. 203)"12; e, por fim, as "cartas envenenadas" enviadas pelos tios que vivem no estrangeiro. A manta de soldado, assimilada a um "atlas" que "a filha de Walter" recebe na casa de Valmares como "única herança" representa claramente o corpo simbólico do destino português, marcado pela guerra, pela viagem, pela errância e pela emigração, isto é, a "mortalha de uma história à vez individual e nacional colocada sob rasura" (FERREIRA, 2001, p. 31)

A vila fictícia de Valmares surge novamente em O vento assobiando nas gruas, para alimentar desta vez uma intriga que se situa na segunda metade dos anos 90, em torno de Milene Leandro, a sobrinha do Presidente da Câmara, jovem órfã oligofrénica que se apaixona por Antonino Mata, um emigrante africano, permitindo a Lídia Jorge encenar a problemática da diferença através de uma reflexão sobre a sociedade multicultural portuguesa, na qual o racismo latente pode assumir dimensões dramáticas. Assim, durante um tórrido mês de Agosto em que todos os tios partiram para férias longínquas, Milene é obrigada a gerir o funeral da avó que foge do hospital e aparece morta em frente da velha fábrica de conservas da 
família, onde vivem os Mata, originários de Cabo Verde (JORGE, 2002). Incapaz de encontrar as palavras justas para contar uma situação altamente perturbadora, a jovem obtém apoio junto dos africanos que lhe oferecem a sua hospitalidade cordial e alguma serenidade. ${ }^{13}$

Acolher o outro na sua estranheza ou na sua singularidade faz também parte do altruismo ou do sentido da responsabilidade inscrita na posição ética de Osvaldo Campos, o herói trágico de Combateremos a sombra, que esconde, na sua Casa da Praia, Rossiana, a jornalista angolana ameaçada de morte por um grupo de traficantes de droga. O psicanalista vive com ela uma breve experiência amorosa, conseguindo salvá-la, graças à cumplicidade de um colega italiano que a põe ao abrigo num convento. Nessa linha, poderíamos ainda evocar o gesto protector de Solange, em $A$ noite das mulheres cantoras, que oferece durante algum tempo um abrigo secreto ao debilitado coreógrafo João de Lucena, seu antigo namorado, para o preservar do oportunismo da maestrina que "queria mostrar em directo a decadência" do dançarino. Essas atitudes afirmam-se por conseguinte como uma resposta à interpelação do Outro que é, "na sua essência amizade e hospitalidade" (DERRIDA, 2004, p. 60), correspondendo à "eticidade propriamente dita, o todo e o princípio da ética", de que fala Derrida ao re-inventar o legado de Levinas, pois só há verdadeiramente responsabilidade moral quando a hospitalidade toma a forma de um dom sem retribuição possível (DERRIDA, 1997).

Ao mobilizar atitudes de grande empatia perante a fragilidade do Outro, Lídia Jorge ilustra em certa medida a ética do care ou do cuidado, ${ }^{14}$ definida como uma actividade que remete para uma realidade banal, permitindo analisar as relações sociais sob a óptica da dependência e da vulnerabilidade e dando lugar a uma "voz diferente", considerada por Carol Gilligan como eminentemente feminina, questão que alimenta ainda hoje numerosos debates, particularmente entre algumas feministas que recusam a dimensão essencialista de tal afirmação. ${ }^{15}$ Contudo, ao mesmo tempo que valoriza a responsabilidade e a hospitalidade enquanto valores morais inseparáveis, Lídia Jorge desconstrói ironicamente as suas potencialidades visto que aqueles que praticam a ética do cuidado acabam mal: o psicanalista generoso de Combateremos a sombra perde a vida e Milene é obrigada, em $O$ vento assobiando nas gruas, a assumir uma perda inscrita como uma cicatriz indelével no seu próprio corpo. Assim, ao pretender casar-se com Antonino Mata, o condutor de gruas cabo-verdiano, a jovem introduz a desordem no mundo burguês a que pertence, fazendo-lhe correr o perigo da "cafrealização" como afirma o motorista do tio, que através dessa expressão revela todo o peso dos preconceitos raciais que vêm de longe. A solução encontrada pela família Leandro - disposta a vender a velha fábrica a especuladores imobiliários holandeses -, vai ser a violenta "castração" de Milene, isto é, a histerectomia praticada sem o seu consentimento na clínica de uma das tias. A escritora testemunha assim, mais uma vez, sobre uma sociedade em que os padrões de comportamento se modificam, 
sublinhando o contraste entre a candura de Milene e os rasgos de traição e intolerância impostos por uma família incapaz de respeitar a liberdade da jovem apaixonada.

Desde a aparente naturalidade polifónica de $O$ dia dos prodígios até ao seu último romance, a preocupação de dar voz aos excluídos faz parte do projeto ético e estético da escrita de Lídia Jorge, que valoriza a subalternidade pondo a falar os camponeses, os emigrantes, os colonizados, os vulneráveis, enfim, todos aqueles que foram excluídos da possibilidade de se tornarem membros plenos do estrato social dominante (SPIVAK, 1988). O solo ético da sua ficção, enquanto campo da escolha, afirma portanto valores e impõe debates, ao valorizar dialogicamente o Outro na sua liberdade, conferindo-lhe a possibilidade de se exprimir na sua diferença e nomeando-o no seu processo de empoderamento ou desempoderamento.

Como acabamos de ver, o poder reconfigurador da obra de Lídia Jorge remete-nos frequentemente para temas ou motivos de teor social, revelando uma estrutura de sentido que sustenta configurações ou desfigurações do sujeito e da linguagem através de uma percepção singular do espaço onde se desenha uma constante reflexão sobre a sociedade portuguesa, tanto colonial como pós-colonial, a partir de experiências individuais ou colectivas que reflectem a maneira como a herança transformada se conjuga com o testemunho para nos transmitir um olhar ético sobre o mundo através de uma prática responsável da literatura, capaz de superar a melancolia e o pavor provocado por algumas "casas assombradas" da nossa cultura. Enquanto arquivo da "matéria-emoção" de uma época inscrita num espaço bem definido, a obra da escritora-testemunha problematiza o presente, ao mesmo tempo que propõe uma revisão crítica do passado, seleccionando cuidadosamente a herança recebida, afirmando uma exigência moral e assumindo um compromisso ou um dever de resposta que é também uma forma de "calçar" metaforicamente o leitor, tal como o sugere a própria Lídia Jorge ao explicitar, nos seguintes termos, o alcance do seu projecto literário: "Se existe alguma coisa de dirigido, durante o processo de criação, talvez seja sobretudo a esperança de que o leitor entenda a minha proposta de alteração ao real. Nesse campo, não nego que escrevo para subverter quando não mesmo para inverter."16

\section{REFERÊNCIAS BIBLIOGRÁFICAS}

ADORNO, Theodor. Notes sur la littérature. Trad. Sibylle Muller. Paris: Flammarion, 1984.

AGAMBEN, Giorgio. Ce qui reste d'Auschwitz. Trad. Pierre Alferi. Paris: Rivages Poche, 1999.

BACHELARD, Gaston . La poétique de l'espace, Paris: PUF, 1957.

BARTHES, Roland. Le bruissement de la langue. Paris: Points Seuil, 1984. 
COLLOT, Michel. La matière-emotion. Paris: PUF, 1997a. . Les enjeux du paysage. Bruxelles: Ousia, $1997 \mathrm{~b}$.

Corti, 2005. . Paysage et poésie - du Romantisme à nos jours. Paris: José

COMPAGNON, Antoine. La littérature pour quoi faire? Paris: Collège de France/Fayard, 2007.

DERRIDA, Jacques. La Dissémination. Paris: Seuil, 1972. . Spectres de Marx. Paris: Galilée, 1993.

. De l'hospitalité. Paris: Calmann-Lévy, 1997.

. Sob Palavra: instantâneos filosóficos. Trad. Miguel Serras Pereira. Lisboa: Fim de Século, 2004.

FELMAN, Shoshana; LAUB, Dori. Testimony. Crises of Witnessing in Litterature, Psychoanalysis and History. New York-Londres: Routledge, 1992.

FERREIRA, Ana Paula. Precisa-se de Pai para Natio de escrita ou A Paixão segundo Lídia Jorge. Mealibra. n. 9, série 3, 2001.

. (org.). Para um leitor ignorado. Ensaios sobre a ficção de Lídia Jorge. Lisboa: Texto Editora, 2009.

FIGUEIREDO, Monica. "Em nome do Pai - a propósito de O Vale da Paixão”. Mealibra. n. 9, série 3, 2001.

. No corpo, na casa e na cidade: as moradas da ficção. Rio de Janeiro: Língua Geral, 2011.

FINKIELKRAUT, Alain (dir.). Ce que peut la littérature. Paris: Stock, 2006.

FREIRE, Paulo. Pedagogia do oprimido. Rio de Janeiro: Paz e Terra, 1981.

GILLIGAN, Carol. Une voix différente. Pour une éthique du care. Paris: Flammarion/Champs, 2008.

JORGE, Lídia. O dia dos prodígios, 2. ed. Lisboa: Europa-América, 1980.

. O cais das merendas. Lisboa: Publicações Europa-América, 1982. 1984.

. A costa dos murmúrios. Lisboa: D. Quixote, 1988.

. A última Dona. Lisboa: D. Quixote, 1992. 
. O jardim sem limites. Lisboa: D.Quixote, 1995.

. Marido e outros contos. Lisboa: D.Quixote, 1997.

. O vale da paixão. Lisboa: D.Quixote, 1998.

. O vento assobiando nas gruas. Lisboa: D.Quixote, 2002.

. Combateremos a sombra. Lisboa: D.Quixote, 2007.

. A noite das mulheres cantoras. Lisboa: D. Quixote, 2011.

KRISTEVA, Julia. Le temps sensible. Proust et l'expérience littéraire. Paris: Gallimard, 1994.

LAUGIER, Sandra. Ethique, littérature, vie humaine. Paris: PUF, 2006.

LÉVINAS, Emmanuel. De l'existence à l'existant. Paris: Vrin, 1986.

MAGALHÃES, Isabel Allegro de.Capelas imperfeitas: configurações literárias da identidade portuguesa. In: RAMALHO, Maria Irene; RIBEIRO, António Sousa (orgs.). Entre Ser e Estar. Raízes, percuros e discursos da identidade. Porto: Afrontamento, 2001.

MEDEIROS, Paulo de. Casas assombradas. In: RIBEIRO, Margarida Calafate; FERREIRA, Ana Paula (org.). Fantasmas e fantasias imperiais no imaginário português contemporâneo. Porto: Campo das Letras, 2003.

NUSSBAUM, Martha. La connaissance de l'amour: essais sur la philosophie et la littérature. Trad. Solange Chavel. Paris: Les Éditions du Cerf, 2010.

RIBEIRO, Margarida Calafate. Uma história de regressos: império, guerra colonial e pós-colonialismo. Porto: Afrontamento, 2004.

RICEUR, Paul. Temps et récit. Paris: Seuil, 1983.

. Soi-même comme un autre. Paris : PUF, 1990.

ROMANO, Jorge, Empoderamento: recuperando a questão do poder no combate à pobreza. Rio de Janeiro: Actionaid, 2002.

SARTRE, Jean-Paul. Situations II. Qu'est-ce que la littérature?, Paris: UGE, 1965.

SEIXO, Maria Alzira. A Palavra do Romance. Ensaios de Genologia e Análise. Lisboa: Livros Horizonte, 1986.

SENA, Jorge de. Poesia I. Lisboa: Edições 70, 1988.

SONTAG, Susan. Diante da Dor dos Outros. S.Paulo: Companhia das Letras, 2003.

SILVEIRA, Jorge Fernandes da (org.). Escrever a casa portuguesa. Belo Horizonte: Editora da UFMG, 1999. 
SPIVAK, Gayatri C. Can the subaltern speak?. In: NELSON, C.; GROSSBERG, L.. (eds.). Marxism and the interpretation of culture. Chicago: University of Illinois, 1988.

TALON-HUGON, Carole. Morales de l'art. Paris: PUF, 2009.

WALLERSTEIN, Nina, e BERNSTEIN, Edward. Introduction to community emporwerment, participation, education, and health. Health Education Quarterly: Special Issue Community Emporwerment, Participatory Education, and Health, I, v. 21, n. 2, 1994.

WIEVIORKA, Annette. Lère du témoin. Paris: Plon, 1998.

Recebido para publicação em 08/04/2013

Aprovado em 22/07/2013

\section{NOTAS}

1 Este texto foi apresentado na exposição bio-bibliográfica "Dia dos Prodígios - Lídia Jorge, 30 anos de escrita publicada", promovida pelo Câmara Municipal de Loulé e patente ao público no Convento de Santo António, de dezembro de 2010 até 31 de Março de 2011. Uma parte desta exposição foi inaugurada em Paris, em Janeiro de 2012, na presença da escritora.

2 Numa entrevista dada a Maria Teresa Horta, Lídia Jorge afirma: "Penso que ponho a minha rebeldia dentro dos meus livros", in Ler, n.40, Outono/Inverno, 1997-1998, p. 40.

3 "Vem aí um carro. Um carro celestial. Celestial. Olhem todos. Traz os anjos e os arcanjos." (Jorge, 1980, p.152).

4 Consultar em particular o importante estudo de Margarida Calafate Ribeiro, Uma história de regressos: império, guerra colonial e pós-colonialismo. Porto: Afrontamento, 2004.

5 Utilizamos aqui a feliz expressão de Julia Kristeva a propósito de Proust in Le temps sensible: Proust et lexpérience littéraire. Paris: Gallimard, 1994, p. 291-347.

6 Numa entrevista dada ao suplemento Mil Folhas-Público, em 24 de Junho de 2002, a propósito da adaptação do seu romance para o cinema, feita por Margarida Cardoso, Lídia Jorge afirma o seguinte: "Livro e filme teriam sido certamente diferentes se assinados por alguém que tivesse feito a guerra, tivesse passado pela experiência directa da morte e do decepamento, ficando assim definitivamente aniquilado para a subtileza. [...] O que me une à Margarida Cardoso foi o termos sido poupadas à experiência directa, é isso que nos permite ter guardado não o distanciamento, mas o olhar da espia."

7 Segundo Michel Collot, "le 'paysage' d'un écrivain ne se réduit à aucun des sites où il a vécu, voyagé ou travaillé. Il n'est pas même un composé plus ou moins subtil de ces référents géographiques et biographiques, mais une constellation originale de signifiés produits pas son œuvre", in Les enjeux du paysage. Bruxelles: Ousia, 1997b, p. 201.

8 Segundo Jorge Fernandes da Silveira, "A casa é cenário das questões-chave, ainda hoje, para a relação dos portugueses com a sua própria história, consigo mesmos" (SILVEIRA, 1999, p. 15).

9 Este aspecto foi desenvolvido por Paulo de Medeiros, "Casas assombradas", in Margarida Calafate Ribeiro e Ana Paula Ferreira (orgs.). Fantasmas e fantasias imperiais no imaginário português contemporâneo, Porto: Campo das Letras, 2003, p. 133.

10 "A ficção é o mais sério de tudo", entrevista de Lídia Jorge a Luis Almeida Martins, Jornal de Letras Artes e Ideias, 29 de Setembro de 1992. 
11 "ela sentia-se a herdeira universal dos desenhos de Walter" (JORGE, 1998, p.24).

12 Sobre este aspecto, consultar também Monica Figueiredo, "Em nome do Pai - a propósito de O Vale da Paixão", in Mealibra, n. 9, série 3, 2001, p. 25.

13 Como afirma Felícia Mata: "A vida podia andar muito malvada noutros locais do Mundo, mas ali pelo menos todos estavam em paz e alegria”, (JORGE, 2002, p. 223).

14 Num estudo intitulado "Capelas imperfeitas: configurações literárias da identidade portuguesa”, Isabel Allegro de Magalhães constatou a proximidade de algumas narrativas femininas sobre a guerra colonial "daquela linha ética a que algumas feministas (...) têm vindo a chamar uma "ética do cuidado", in Maria Irene Ramalho, António Sousa Ribeiro (org.). Entre ser e estar. raízes, percuros e discursos da identidade. Porto: Afrontamento, 2001, p. 340.

15 Carol Gilligan. Une voix différente. Pour une éthique du care [1982]. Paris: Flammarion/ Champs, 2008. Consultar ainda sobre esta questão Joan Tronto, Un Monde Vulnérable. Pour une politique du care. Paris: La Découverte, 2003.

16 Entrevista com Ana Paula Ferreira (2009, p. 340). 